\title{
Comparison of Efficacy of Oral Antidiabetic Drugs versus Combination of Oral Antidiabetic Drugs along with Insulin in Management of Diabetes Mellitus - A Retrospective Study
}

\author{
Kunal Gupta ${ }^{1}$, Saurav Deka ${ }^{2}$, Betina Chandolia ${ }^{3}$, Raman Gupta ${ }^{4}$ \\ ${ }^{1}$ MBBS, MD, Diabetologist, Kosmos Superspeciality Hospital, Delhi NCR \\ ${ }^{2}$ MBBS, MD, AVP, RWE, THB Sekhmet Technologies, Gurgaon \\ ${ }^{3}$ BDS, MDS, Medical Writer, RWE, THB Sekhmet Technologies, Gurgaon \\ ${ }^{4} \mathrm{BSc}$, MSc, Biostatistician, RWE, THB Sekhmet Technologies, Gurgaon \\ Corresponding Author: Kunal Gupta
}

DOI: https://doi.org/10.52403/ijshr.20220108

\begin{abstract}
Objective: To compare the efficacy of oral antidiabetic drugs (OADs) versus combination of OADs along with insulin in Type 2 Diabetes Mellitus patients.

Methods: A retrospective study was conducted in which data was extracted from the electronic medical records. Two groups were formed, Group I comprised of nineteen patients who were prescribed OADs while in Group II, five patients were prescribed combination of OADs and insulin therapy from January 2020 to June 2021. Blood glucose parameters (HbA1c, FBS, PPBS) were noted at baseline and subsequent next three follow-ups. The statistical analysis was done using SPSS version 26.0.
\end{abstract}

Results: The diabetic patients on the combination therapy showed better improvement as compared to the diabetic patients who were prescribed only OADs. However, the differences between the blood glucose parameters were found to be nonsignificant.

Conclusion: In the case of patients where targeted glucose levels are not achieved with OADs alone, combination therapy can be prescribed comprising of OADs and insulin therapy to get better-controlled results.

Keywords: Oral antidiabetic drugs (OADs), combination of OADs \& insulin, Type 2 Diabetes Mellitus, T2DM, diabetic patients

\section{INTRODUCTION}

The increasing ubiquity of Type 2 diabetes Mellitus (T2DM) and its related complications pose a significant global health care burden (1). A diabetes study by landmark U.K stated the benefits of improved glucose control and accentuated the progressive nature of type 2 diabetes because of $\beta$-cell failure. The study suggested that about $50 \%$ of patients with type 2 diabetes may require insulin therapy along with oral antidiabetic drugs (OADs) within six years of diabetes diagnosis $(2,3)$. The American Diabetes Association clinical guidelines and European Association for the Study of Diabetes recommend commencing basal insulin in patients with type 2 diabetes either directly after metformin or after intensifying a combination of OADs with or without glucagonlike peptide-1 receptor agonists and then evaluating insulin to achieve hbalc target of $7 \%$ without notable hypoglycemia $(4,5)$.

Various roadblocks to introducing insulin have been recognized that may result in hampered achievement of glycemic control and progression of complications of diabetes $(6,7)$. These roadblocks include patients' anxiety towards injections and misconceptions about insulin therapy, clinicians' apprehension of perceived 
Kunal Gupta et.al. Comparison of efficacy of oral antidiabetic drugs versus combination of oral antidiabetic drugs along with insulin in management of diabetes mellitus - a retrospective study.

complexity of insulin regimens (8). Other significant limiting factor in maximizing insulin therapy and optimizing glycemic control include the risk, consequences, and fear of hypoglycemia (9).

Our study aimed to compare the efficacy of OADs versus the combination of OADs and insulin therapy in type 2 diabetes mellitus patients.

\section{MATERIALS AND METHODS}

We conducted a retrospective study in which the data was extracted from electronic medical records. A total of 24 patients had four visits from the period of January 2020 to June 2021. Out of the 24 patients, 19 patients (Group I) were prescribed OADs while five patients (Group II) were prescribed combination of OADs and insulin therapy. Various blood glucose parameters including glycated hemoglobin (HbA1c), fasting blood sugar (FBS), post prandial blood sugar (PPBS) were noted at baseline and subsequent next three followups. The statistical analysis was done using SPSS version 26.0.

\section{RESULTS}

The mean values for the various blood glucose parameters were calculated and statistically analyzed. The mean values with standard deviation along with p-values are shown in Table 1.

\begin{tabular}{|c|c|c|c|}
\hline \multirow[t]{2}{*}{ Group } & \multirow{2}{*}{$\begin{array}{l}\text { Group I (OADs, } \mathbf{n = 1 9 )} \\
\text { Mean } \pm \text { SD }\end{array}$} & \multirow{2}{*}{$\begin{array}{l}\text { Group II (OADs + Insulin, } \mathbf{n = 5}) \\
\text { Mean } \pm \text { SD }\end{array}$} & \multirow[t]{2}{*}{ p-value } \\
\hline & & & \\
\hline \multicolumn{4}{|l|}{ Hba1c } \\
\hline Baseline & $6.89 \pm 1.04$ & $7.52 \pm 2.38$ & 0.91 \\
\hline Follow-Up Visit 1 & $6.45 \pm 1.00$ & $7.42 \pm 2.53$ & 0.64 \\
\hline Improvement $(0-1)$ & 0.44 & 0.10 & 0.67 \\
\hline$p$-value & 0.12 & 0.50 & - \\
\hline Follow-Up Visit 2 & $6.89 \pm 0.70$ & $6.58 \pm 0.67$ & 0.39 \\
\hline Improvement $(0-2)$ & 0.00 & 0.94 & 0.92 \\
\hline p-value & 0.69 & 0.89 & - \\
\hline Follow-Up Visit 3 & $6.26 \pm 0.17$ & $6.19 \pm 0.12$ & 0.58 \\
\hline Improvement (0-3) & 0.63 & 1.33 & 0.92 \\
\hline$p$-value & 0.02 & 0.22 & - \\
\hline \multicolumn{4}{|l|}{ FBS } \\
\hline Baseline & $117.59 \pm 21.14$ & $155.60 \pm 73.49$ & 0.24 \\
\hline Follow-Up Visit 1 & $115.03 \pm 21.89$ & $132.34 \pm 76.50$ & 0.78 \\
\hline Improvement (0-1) & 2.56 & 23.26 & 0.04 \\
\hline$p$-value & 0.60 & 0.04 & - \\
\hline Follow-Up Visit 2 & $111.61 \pm 10.73$ & $113.05 \pm 9.41$ & 0.78 \\
\hline Improvement (0-2) & 5.98 & 42.55 & 0.27 \\
\hline p-value & 0.33 & 0.08 & - \\
\hline Follow-Up Visit 3 & $129.07 \pm 5.02$ & $127.30 \pm 7.53$ & 0.64 \\
\hline Improvement (0-3) & -11.48 & 28.30 & 0.21 \\
\hline p-value & 0.33 & 0.08 & - \\
\hline \multicolumn{4}{|l|}{ PPBS } \\
\hline Baseline & $164.42 \pm 38.09$ & $204.17 \pm 59.39$ & 0.22 \\
\hline Follow-Up Visit 1 & $185.89 \pm 33.02$ & $212.55 \pm 68.53$ & 0.34 \\
\hline Improvement (0-1) & -21.46 & -8.38 & 0.34 \\
\hline p-value & 0.01 & 0.50 & - \\
\hline Follow-Up Visit 2 & $172.92 \pm 19.47$ & $164.55 \pm 16.02$ & 0.41 \\
\hline Improvement (0-2) & -8.49 & 39.62 & 0.09 \\
\hline$p$-value & 0.21 & 0.35 & - \\
\hline Follow-Up Visit 3 & $159.52 \pm 10.20$ & $164.80 \pm 5.29$ & 0.09 \\
\hline Improvement (0-3) & 4.90 & 39.36 & 0.19 \\
\hline$p$-value & 0.63 & 0.14 & - \\
\hline
\end{tabular}

The comparison between Group I and Group II for HbA1c is shown in Graph 1. 
Kunal Gupta et.al. Comparison of efficacy of oral antidiabetic drugs versus combination of oral antidiabetic drugs along with insulin in management of diabetes mellitus - a retrospective study.

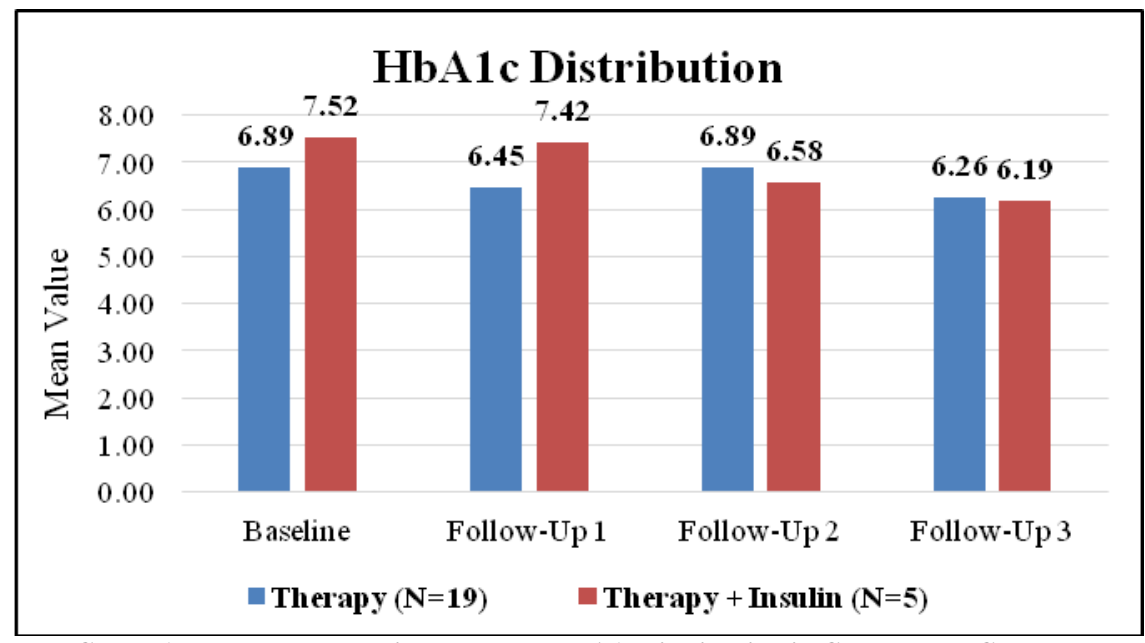

Graph 1 shows the comparison between HbA1c distribution in Group I and Group II

The comparison between Group I and Group II for FBS is shown in Graph 2.

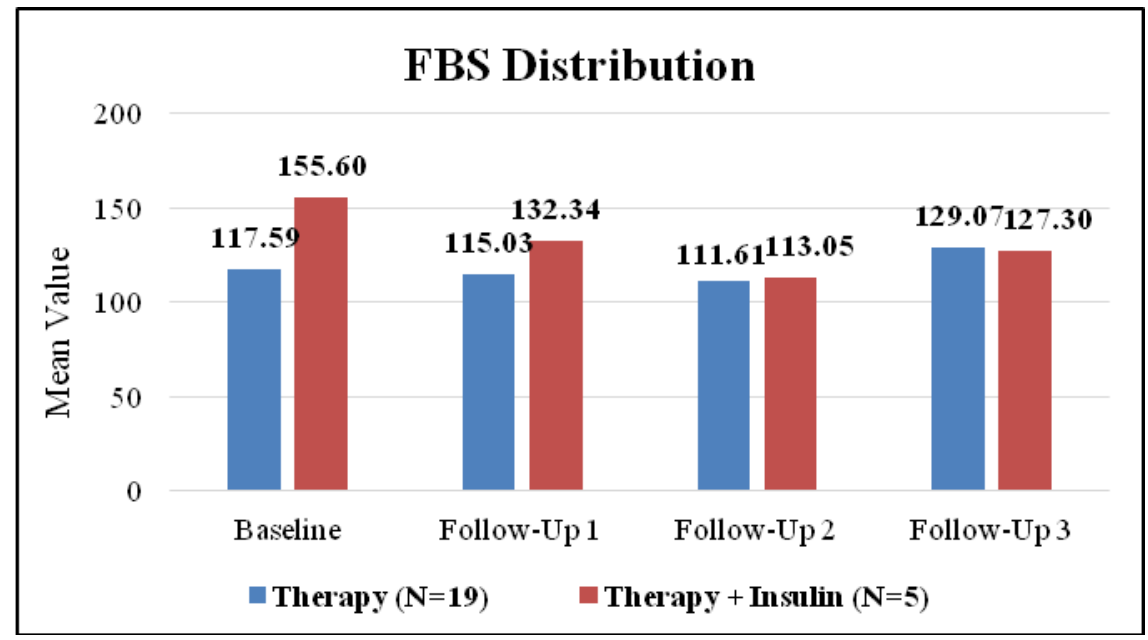

Graph 2 shows the comparison between FBS distribution in Group I and Group II

The comparison between PPBS distribution for Group I and Group II is shown in Graph 3.

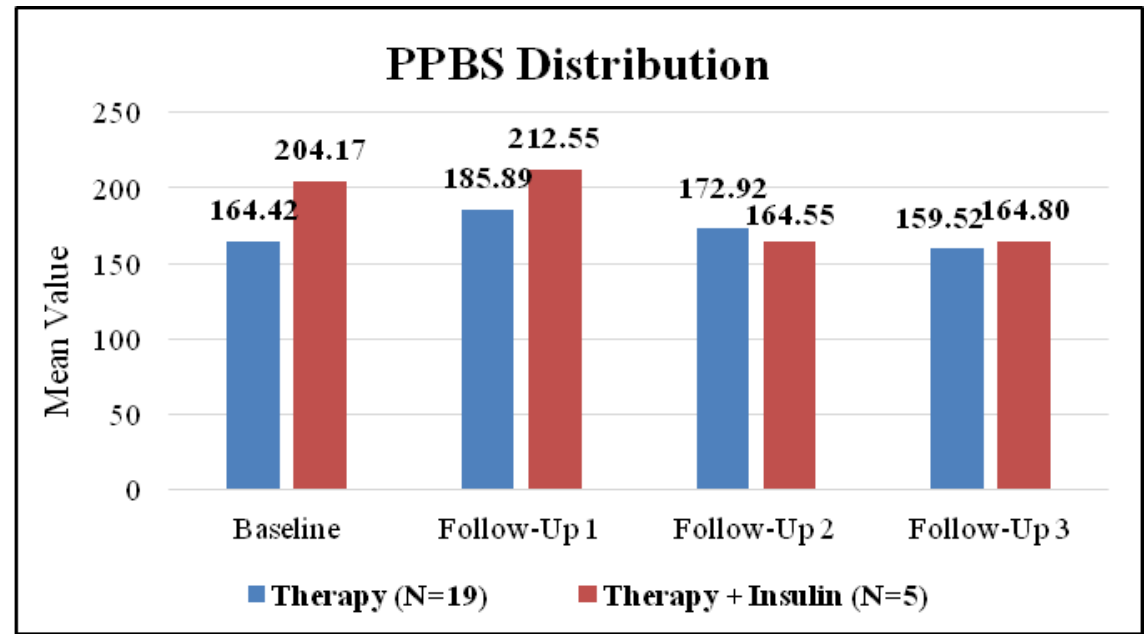

Graph 3 shows the comparison between PPBS distribution in Group I and Group II 
Kunal Gupta et.al. Comparison of efficacy of oral antidiabetic drugs versus combination of oral antidiabetic drugs along with insulin in management of diabetes mellitus - a retrospective study.

None of the comparisons were found to be statistically significant. However, Group II showed greater improvement for various blood glucose parameters when compared with Group I in subsequent follow-ups.

\section{DISCUSSION}

Both the groups showed reduction in HbA1c, FBS, and PPBS levels. However, the improvement was seen more in Group II in which OADs were prescribed along with insulin therapy to T2DM patients. However, these findings were not clinically significant.

Liu et al carried-out a study in diabetic patients in which they found that it was safe and effective to control glycemic parameters using basal insulin glarginebased therapy plus OADs compared with twice-daily premixed insulin (10). Randomized controlled trials have been conducted in which Insulin degludec and glargine was administered once daily in combination with OADs, and it provided similar long-term glycemic control in type 2 diabetes insulin-naive patients, with lower rates of nocturnal hypoglycemia with degludec (11).

OADs are prescribed for the treatment of T2DM Studies have shown that OAD along with insulin analogs can help patients to achieve better glycemic control. OAD therapy along with basal insulin analog helps to improve $\mathrm{HbA} 1 \mathrm{c}$ by $1.5 \%$ to $1.8 \%$, with a low risk of hypoglycemic events. Greater HbA1c reductions have been shown by premixed insulin analogs, but considerable weight gain has also been noted. Few studies have shown that the long-acting insulin analog detemir has been seen to limit the weight gain which is normally present with the use of insulin (12).

More studies need to be conducted on a larger sample size to further signify the improvement in glucose parameters in diabetics with combination therapy of insulin with OADs.

\section{CONCLUSION}

In diabetic patients, as compared to drug therapies, combination therapy of insulin with OADs can provide better improvement in glucose parameter levels. However, further studies need to be carried out to reach on a bigger conclusion.

\section{Acknowledgement: None}

\section{Conflict of Interest: None}

\section{Source of Funding: None}

\section{Ethical Approval: Approved}

\section{REFERENCES}

1. International Diabetes foundation. Diabetes atlas 5th edition [article online], 2011. Available from http://www.idf.org/diabetesatlas/5e/theglobal-burden. Accessed 13 December 2021.

2. U.K. Prospective Diabetes Study Group. UKPDS 28: a randomized trial of efficacy of early addition of metformin in sulfonylurea-treated type 2 diabetes. Diabetes Care 1998;21:87-92pmid:9538975

3. Wright A, Burden AC, Paisey RB, Cull CA, Holman RR, U.K. Prospective Diabetes Study Group. Sulfonylurea inadequacy: efficacy of addition of insulin over 6 years in patients with type 2 diabetes in the U.K. Prospective Diabetes Study (UKPDS 57). Diabetes Care 2002;25:330 336pmid:11815505

4. American Diabetes Association. Standards of medical care in diabetes-2011. Diabetes Care 2011;34(Suppl. 1):S11S61pmid:21193625

5. Inzucchi SE, Bergenstal RM, Buse JB, et al. Management of hyperglycaemia in type 2 diabetes: a patient-centered approach. Position statement of the American Diabetes Association (ADA) and the European Association for the Study of Diabetes (EASD). Diabetologia 2012;55:15771596pmid:225266

6. UK Prospective Diabetes Study (UKPDS) Group. Intensive blood-glucose control with sulphonylureas or insulin compared with conventional treatment and risk of complications in patients with type 2 
Kunal Gupta et.al. Comparison of efficacy of oral antidiabetic drugs versus combination of oral antidiabetic drugs along with insulin in management of diabetes mellitus - a retrospective study.

diabetes (UKPDS 33). Lancet 1998; 352:837-853pmid:9742976

7. Yki-Järvinen $\mathrm{H}$, Ryysy L, Nikkilä K, Tulokas T, Vanamo R, Heikkilä M. Comparison of bedtime insulin regimens in patients with type 2 diabetes mellitus. A randomized, controlled trial. Ann Intern Med 1999;130:389-396pmid:10068412

8. Meece J. Dispelling myths and removing barriers about insulin in type 2 diabetes. Diabetes Educ 2006;32(Suppl):9S18Spmid: 16439485

9. Cryer PE. Hypoglycaemia: the limiting factor in the glycaemic management of Type I and Type II diabetes. Diabetologia 2002;45:937-948pmid:12136392

10. Liu J, Jiang $X, X u B$, Wang G, Cui N, Zhang X, Liu J, Mu Y, Guo L. Efficacy and Safety of Basal Insulin-Based Treatment Versus Twice-Daily Premixed Insulin After Short-Term Intensive Insulin Therapy in Patients with Type 2 Diabetes Mellitus in China: Study Protocol for a Randomized Controlled Trial (BEYOND V). Adv Ther. 2020 Apr;37(4):1675-1687. doi: 10.1007/s12325-020-01265-6. Epub 2020 Mar 4. PMID: 32130661.
11. Zinman B, Philis-Tsimikas A, Cariou B, Handelsman Y, Rodbard HW, Johansen T, Endahl L, Mathieu C; NN1250-3579 (BEGIN Once Long) Trial Investigators. Insulin degludec versus insulin glargine in insulin-naive patients with type 2 diabetes: a 1-year, randomized, treat-to-target trial (BEGIN Once Long). Diabetes Care. 2012 Dec;35(12):2464-71. doi: 10.2337/dc121205. Epub 2012 Oct 5. PMID: 23043166; PMCID: PMC3507614.

12. Hermansen K, Mortensen LS, Hermansen ML. Combining insulins with oral antidiabetic agents: effect on hyperglycemic control, markers of cardiovascular risk and disease. Vasc Health Risk Manag. 2008; 4(3):561-574. doi:10.2147/vhrm.s1815

How to cite this article: Gupta K, Deka S, Chandolia B et.al. Comparison of efficacy of oral antidiabetic drugs versus combination of oral antidiabetic drugs along with insulin in management of diabetes mellitus - a retrospective study. International Journal of Science \& Healthcare Research. 2022; 7(1): 4145. DOI: https://doi.org/10.52403/ijshr. 20220108 